\title{
Estimation of Surface Water Vapour Density and Its Variation with Other Meteorological Parameters Over Owerri, South Eastern, Nigeria
}

\author{
Davidson Odafe Akpootu ${ }^{1, \text { *, Wahidat Mustapha }}{ }^{2}$, Ashiru Muhammad Rabiu ${ }^{3}$, \\ Mukhtar Isah Iliyasu ${ }^{4}$, Mohammed Bello Abubakar ${ }^{4}$, Serah Omolola Yusuf ${ }^{5}$, \\ Simeon Imaben Salifu ${ }^{6}$ \\ ${ }^{1}$ Department of Physics, Usmanu Danfodiyo University, Sokoto, Nigeria \\ ${ }^{2}$ Nigerian Meteorological Agency (NIMET), Abuja, Nigeria \\ ${ }^{3}$ Sokoto Energy Research Centre, Usmanu Danfodiyo University, Sokoto, Nigeria \\ ${ }^{4}$ Physics Unit, Umaru Ali Shinkafi Polytechnic, Sokoto, Nigeria \\ ${ }^{5}$ Department of Physics, Arthur Jarvis University, Calabar, Nigeria \\ ${ }^{6}$ Department of Physics, Kogi State College of Education Technical, Kabba, Nigeria
}

Email address:

davidson.odafe $a$ udusok.edu.ng (D. O. Akpootu), profdon03 ayahoo.com (D. O. Akpootu)

${ }^{*}$ Corresponding author

\section{To cite this article:}

Davidson Odafe Akpootu, Wahidat Mustapha, Ashiru Muhammad Rabiu, Mukhtar Isah Iliyasu, Mohammed Bello Abubakar, Serah Omolola Yusuf, Simeon Imaben Salifu. Estimation of Surface Water Vapour Density and Its Variation with Other Meteorological Parameters Over Owerri, South Eastern, Nigeria. Hydrology. Vol. 7, No. 3, 2019, pp. 46-55. doi: 10.11648/j.hyd.20190703.12

Received: August 26, 2019; Accepted: September 18, 2019; Published: October 9, 2019

\begin{abstract}
In this paper, the monthly variation of Surface Water Vapour Density (SWVD) with meteorological parameters of monthly average daily mean temperature, relative humidity, surface pressure, cloud cover and sunshine hours during the period of sixteen years $(2000-2015)$ for Owerri (Latitude $5.48^{\circ} \mathrm{N}$, Longitude $7.00^{\circ} \mathrm{E}$, and $91 \mathrm{~m}$ above sea level) were investigated. The daily variation of surface water vapour density for the two distinct seasons considering two typical months in each during the period of year 2015 was examined. The results showed fluctuation in the amount of surface water vapour density in each day of the month for the period under investigation. The monthly average daily values indicated that the surface water vapour densities are greater during the raining season than in the dry season. It was observed that the maximum average value of surface water vapour density of $21.002 \mathrm{gm}^{-3}$ occurred in the month of June during the raining season and minimum value of $14.653 \mathrm{gm}^{-3}$ in the month of January during the dry season. The highest value of surface water vapour density was observed on $9^{\text {th }}$ May, 2015 and the lowest on $14^{\text {th }}$ January, 2015. The comparison assessment of the developed SWVD based models was carried out using statistical indices of coefficient of determination $\left(\mathrm{R}^{2}\right)$, Mean Bias Error (MBE), Root Mean Square Error (RMSE), Mean Percentage Error (MPE), Nash - Sutcliffe Equation (NSE) and Index of Agreement (IA). The developed multivariate correlation regression model that relates temperature and relative humidity with $\mathrm{R}^{2}=99.9 \% \mathrm{MBE}=0.1259 \mathrm{RMSE}=0.1462 \mathrm{MPE}=-0.6739 \mathrm{NSE}=99.8402 \%$ and $\mathrm{IA}=99.9611 \%$ was found more suitable for surface water vapour density estimation with good fitting and therefore can be used for estimating surface water vapour density in the location under investigation and region with similar climatic information. The results of the descriptive statistical analysis revealed that the surface water vapour density, mean temperature, relative humidity, cloud cover and sunshine hours data spread out more to the left of their mean value (negatively skewed), while the surface pressure data spread out more to the right of their mean value (positively skewed). The surface water vapour density data have positive kurtosis which indicates a relatively peaked distribution and possibility of a leptokurtic distribution while the mean temperature, relative humidity, surface pressure, cloud cover and sunshine hours data have negative kurtosis which indicates a relatively flat distribution and possibility of platykurtic distribution.
\end{abstract}

Keywords: Surface Water Vapour Density, Raining Season, Dry Season, Mean Temperature and Relative Humidity 


\section{Introduction}

The connection between the surface and the atmosphere in the hydrological cycle is normally referred to as Water vapour. Virtually all the water vapour in the atmosphere originated at the surface of the earth where water evaporates from the ocean and the continents owning to the sun's radiation and is transpired by plants and respired by animals into the atmosphere [1]. The atmosphere and the water vapour can be transported horizontally and vertically through the three-dimensional circulation of the atmosphere and may condense forming liquid water or ice crystals in clouds; when water returns to the earth's surface in different forms of precipitation such as rain or snow the cycle is said to be completed. The cycle is closely related to the atmospheric circulation and temperature patterns [2]. Approximately two third of the natural green house effect of the earth's atmosphere are caused by water vapour, as a result of this, may be considered the most important greenhouse gas [3].

As the Earth's surface temperature increases, the atmosphere tends to hold more water vapour. This atmospheric water vapour, acts as a greenhouse gas thereby absorbing energy that would otherwise cause attenuation of electromagnetic radiation travelling through the atmosphere, the consequences of these could be atmospheric or global warming. The proportion by volume of water vapour in the air at the ground level on the average changes from less than $0.001 \%$ in the arctic to more than $6 \%$ in the tropics [4]. This proportion decreases speedily with height [4].

The balance between the incoming radiation from the sun and the outgoing reflected and scattered solar radiation plus the thermal infrared emission to space is referred to as the Earth's Radiation Budget (ERB) and is significantly influenced by the Earth's surface conditions through surface water vapour and temperature variations in the thermal infrared and through a critical contribution of temperature to the planetary albedo particularly for desert areas and snow- and ice-covered polar areas [5-6]. The atmospheric water vapour content responds to variations in temperature, microphysical processes and the atmospheric circulation. An overarching consideration is that the highest quantity of water vapour air can hold increases rapidly with temperature, in accordance with the Clausius- Clapeyron equation [7]. This affects all aspects of the hydrological cycle [7].

Researches on climate models have shown that an increase in atmospheric humidity by $12-25 \%$ will have the same global average radiative effect than doubling the Carbon (iv) oxide concentration [5]. On the contrary to the homogeneous distribution of long-lived Carbon (iv) oxide, water vapour distribution is highly variable in space and time. Apart from its direct radiative effect, water vapour acts indirectly by interacting with aerosols, clouds and precipitation [8-9]. This indirect effect of surface cooling offers one of the largest uncertainties in the understanding of the radiative balance of the earth's atmosphere [10].

The aim of this study was to investigate the daily and monthly variation of surface water vapour density and to examine the monthly variation with meteorological parameters of mean temperature, relative humidity, surface pressure, cloud cover and sunshine hours for Owerri located in South Eastern, Nigeria. The study also developed new model for estimating surface water vapour density and descriptive statistical analysis was carried out for the location under investigation.

\section{Study Area}

Figure 1 shows the study area under investigation. Imo is a state in Nigeria located in south eastern Nigeria. Owerri (Latitude $5.48^{\circ} \mathrm{N}$, Longitude $7.00^{\circ} \mathrm{E}$, and $91 \mathrm{~m}$ above sea level) is the capital city of Imo and one of the largest in the state. The State is bordered by Abia State on the East, River Niger and Delta State to the West, Anambra State on the North and Rivers State to the South. The changes that occur as a result of rising surface temperature and rainfall, the area is likely vulnerable to the consequences of global warming [11]. Two seasons are identified, wet and dry seasons. The rainy season is from April to October while the dry season is from November to March. Double maxima, with the first maximum in June and the second in September also characterized the climate. There is therefore a "little dry season" in-between known as "August Break" brought about by the seasonal north and southward movement of the ITCZ (InterTropical Convergence Zone). An average annual temperature above $20^{\circ} \mathrm{C}\left(68.0^{\circ} \mathrm{F}\right)$ creates an annual relative humidity of $75 \%$, with humidity reaching $90 \%$ in the rainy season [11]. The dry season experiences two months of Harmattan from late December to late February. January and March are the hottest months [11].

Imo state has three main political zones; this are, Okigwe (Imo North), Orlu (Imo West) and Owerri (Imo East). According to Okorie [12], the state has a population of about $3,927,563$ with male, $1,976,471$ and female $1,951,092$. The state is blessed with natural resources which include crude oil, natural gas, lead and zinc. Economically exploitable flora like the iroko, mahogany, obeche, bamboo, rubber tree and oil palm predominate [11]. 


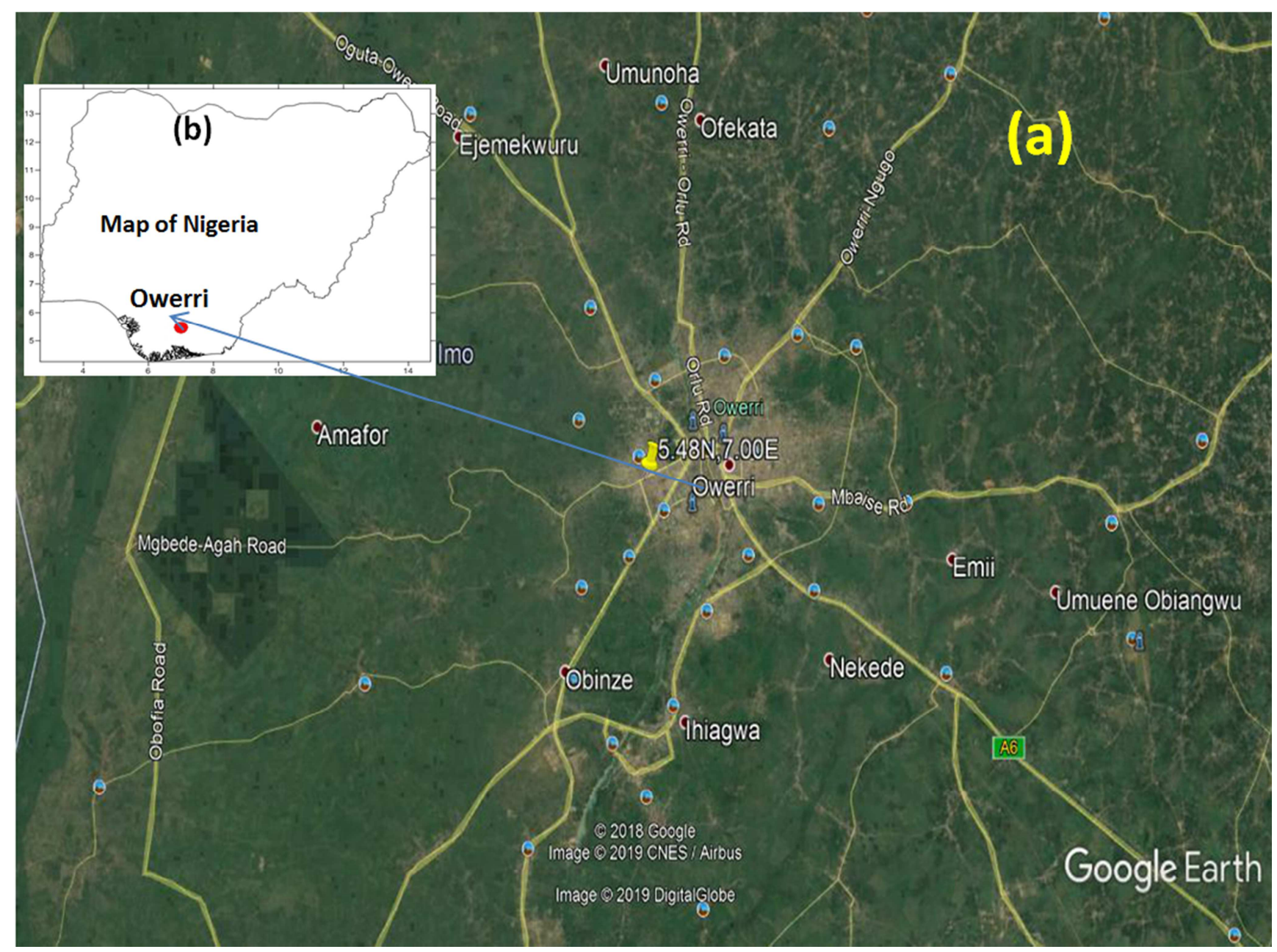

Figure 1. Map of (a) Google map showing the study area (b) Map of Nigeria showing the study area.

\section{Methodology}

The daily and monthly average minimum temperature, maximum temperature, relative humidity, surface pressure, cloud cover and sunshine hours meteorological data used in this study were obtained from the European Centre for Medium-Range Weather Forecasts (ECMWF) at $2 \mathrm{~m}$ height for Owerri, Imo state located in the South Eastern, Nigeria during the period of sixteen years $(2000-2015)$.

The surface water vapour density (SWVD), vapour pressure (e) and mean temperature $(\mathrm{T})$ are related by the following expression $[2,4]$ as:

$$
S W V D=216.7\left(\frac{e}{T}\right)
$$

The vapour pressure $e$ was obtained using the expression given by Adeyemi and Ogolo [2] as:

$$
e=R H\left(\frac{e_{S}}{100}\right)
$$

where $R H$ and $e_{s}$ are the relative humidity and saturated vapour pressure respectively. The saturated vapour pressure was evaluated using the Claussius Clapeyron equation defined as:

$$
\log _{10} e_{s}=9.4051-\left(\frac{2353}{T}\right)
$$

The mean temperature, $\mathrm{T}$ was obtained using

$$
T=\frac{T_{\max }+T_{\min }}{2}
$$

where $T_{\max }$ and $T_{\min }$ are the maximum and minimum temperatures respectively. The $S W V D$ is in $\mathrm{gm}^{-3}, e$ and $e_{S}$ in millibars $(\mathrm{mb}), T$ in Kelvin $(K)$ and $R H$ in percentage (\%).

In this study, the regression models for SWVD estimations are of the forms

$$
\begin{array}{r}
S W V D=a+b T_{\text {mean }}+c R H \\
S W V D=d+e S P+f C C \\
S W V D=g+h S P+i S S H \\
S W V D=j+k C C+l S S H
\end{array}
$$

where $a, b, c, d, e, f, g, h, i, j, k$ and $l$ are empirical SWVD constants.

The validation of the estimated values was statistically tested by computing the Mean Bias Error (MBE), Root Mean Square Error (RMSE), Mean Percentage Error (MPE), Nash- 
Sutcliffe equation (NSE) and the Index of Agreement (IA), similarly. The coefficient of determination $\left(R^{2}\right)$ was determined for each of the models. The expressions for the MBE, RMSE and MPE as stated according to El-Sebaii and Trabea[13] are given as follows.

$$
\begin{gathered}
M B E=\frac{1}{n} \sum_{i=1}^{n}\left(S W V D_{i, \text { cal }}-S W V D_{i, \text { mea }}\right) \\
R M S E=\left[\frac{1}{n} \sum_{i=1}^{n}\left(S W V D_{i, \text { cal }}-S W V D_{i, \text { mea }}\right)^{2}\right]^{\frac{1}{2}} \\
M P E=\frac{1}{n} \sum_{i=1}^{n}\left(\frac{S W V D_{i, \text { mea }}-S W V D_{i, c a l}}{S W V D_{i, \text { mea }}}\right) * 100
\end{gathered}
$$

The Nash-Sutcliffe equation (NSE) is given by the expression

$$
N S E=1-\frac{\sum_{1}^{n}\left(S W V D_{i, m e a}-S W V D_{i, c a l}\right)^{2}}{\sum_{1}^{n}\left(S W V D_{i, \text { mea }}-\overline{S W V D}_{i, \text { meas }}\right)^{2}}
$$

The Index of Agreement (IA) is given as

$$
I A=1-\frac{\sum_{i=1}^{n}\left(S W V D_{i, c a l}-S W V D_{i, m e a}\right)^{2}}{\sum_{i=1}^{n}\left(\left|S W V D_{i, c a l}-\overline{S W V D}_{i, \text { mea }}\right|+\left|S W V D_{i, \text { ea }}-\overline{S W V D}_{i, \text { mea }}\right|\right)^{2}}
$$

From equations (9) - (13) $S W V D_{i, \text { mea }}, S W V D_{i, c a l}$ and $n$ are respectively the $i^{\text {th }}$ measured and $i^{\text {th }}$ calculated values of daily surface water vapour density and the total number of observations, also $\overline{S W V D}_{i, \text { mea }}$ is the mean surface water vapour density.

Chen et al. [14] have recommended that a zero value for MBE is ideal and a low RMSE is desirable. Similarly, the smaller the value of the MBE and RMSE the better is the performance of the model, a positive MPE and MBE values provide the averages amount of overestimation in the calculated values, while the negative values gives underestimation. A low value of MPE is desirable. The percentage error between $-10 \%$ and $+10 \%$ is considered acceptable [15]. High values of $\mathrm{R}^{2}$, NSE and IA are desirable. The MBE and the RMSE are in $\mathrm{gm}^{-3}$, while $\mathrm{R}^{2}$, MPE, NSE and IA are in percentage (\%).

The skewness and kurtosis tests were studied in this present work. The skewness test $\left(\sigma_{k}\right)$ measures the asymmetry of the parameters data around their mean value; it is a measure of symmetry, or more precisely, the lack of symmetry [16]. It informs us about the direction of variation of the dataset [16]. If $\sigma_{k}=0$, the data have a Gaussian distribution (normal distribution), while $\sigma_{k}<0$ indicates that the data are spread out more to the left of the mean value than to its right (negatively skewed), when $\sigma_{k}>0$ indicates that data are spread out more to the right than to its left (positively skewed) [17].

The Kurtosis test $\left(k_{u}\right)$ describes the shape of a random variable's probability distribution, that is it characterizes the relative peakedness or flatness of a distribution compared to the normal distribution [16]. It measures the degree of normality of each of the meteorological parameters under investigation [17]. For $k_{u}=0$ the data have normal distribution, for $k_{u}>0$ the data have positive kurtosis which implies peaked distribution, that is, leptokurtic distribution (that is, too tall), when $k_{u}<0$ the data have negative kurtosis signifying flat distribution, that is, platykurtic distribution (that is, too flat, or even concave if the value is large enough).

\section{Results and Discussion}

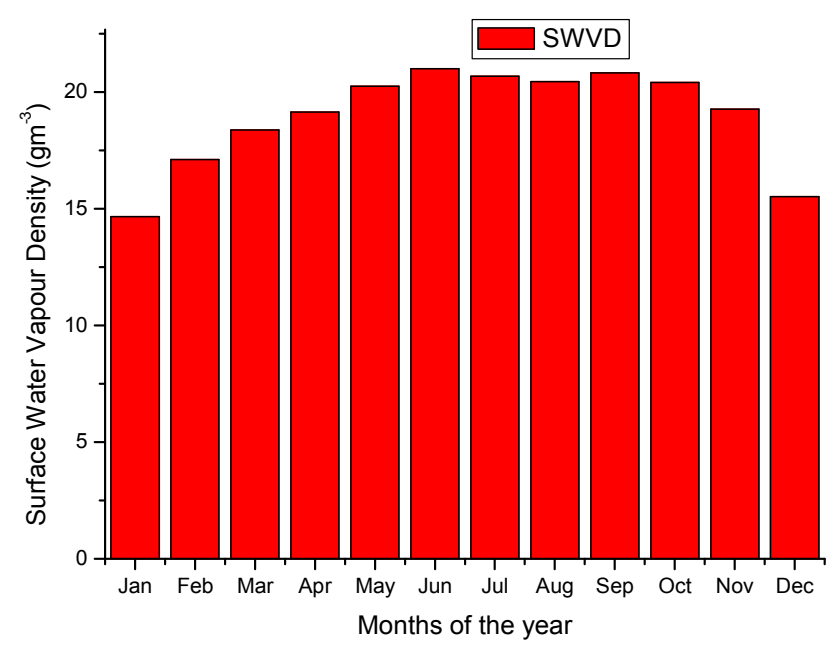

Figure 2. Monthly variation of Surface Water Vapour Density at Owerri, Nigeria.

Figure 2 shows the monthly variation of Surface Water Vapour Density (SWVD) during the period under investigation for the study area. The result revealed that the SWVD during the raining season is greater than in the dry season. It was observed that the maximum average value of SWVD of $21.002 \mathrm{gm}^{-3}$ and minimum value of $14.653 \mathrm{gm}^{-3}$ occurred during the raining and dry seasons in the months of June and January respectively. It was observed that the values of SWVD decreases in the month of July and August immediately after its maximum value in the month of June and later increases in the month of September; this observation is in line with the result reported by Adeyemi and Ogolo [2] for Ikeja and Ibadan located in the Southern zone of Nigeria.

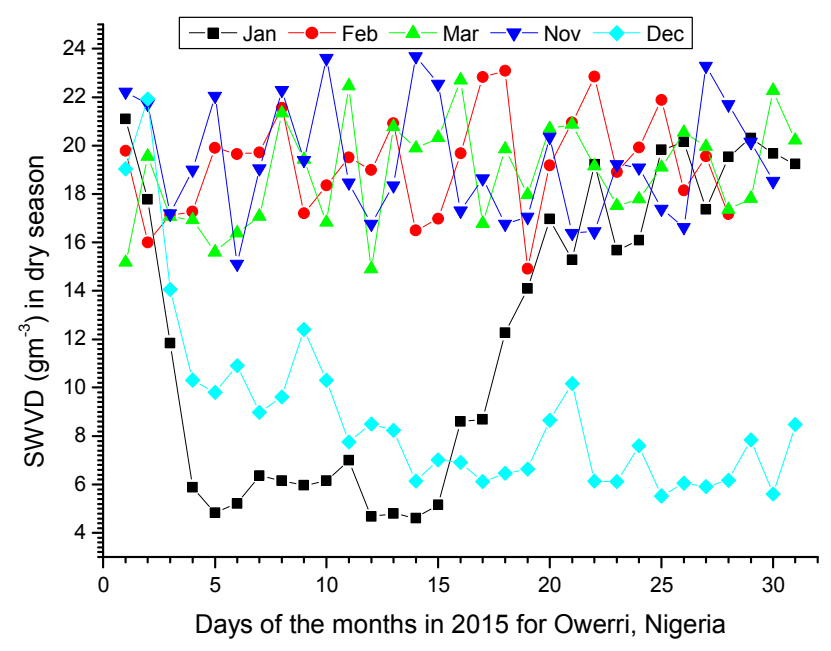

Figure 3. Surface Water Vapour Density during the dry season for Owerri, Nigeria. 
Figure 3 shows the SWVD during the dry season for the location under investigation. The result showed fluctuation in the amount of SWVD with the least values in the months of January and December respectively.

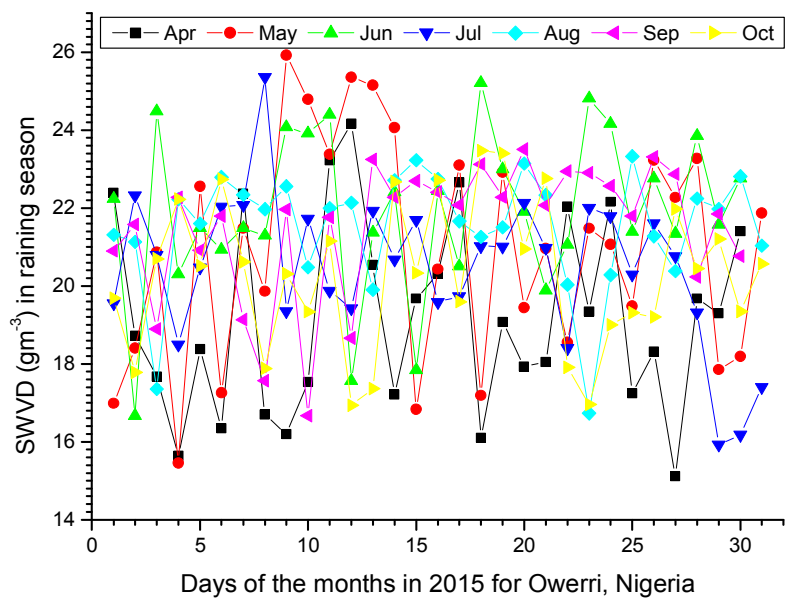

Figure 4. Surface Water Vapour Density during the raining season for Owerri, Nigeria.

Figure 4 shows the SWVD during the raining season for the location under investigation. The result showed fluctuation in the amount of SWVD with the highest values in the months of June and September respectively.

Figure 5 is an extraction of figure 2. The maximum and minimum values of SWVD obtained in the month of January 2015 for the location under study are on the $1^{\text {st }}$ and $14^{\text {th }}$ with SWVD of $21.098 \mathrm{gm}^{-3}$ and $4.610 \mathrm{gm}^{-3}$ respectively. The SWVD decreases from its maximum value of $21.098 \mathrm{gm}^{-3}$ on the $1^{\text {st }}$ January 2015 to $4.836 \mathrm{gm}^{-3}$ on the $5^{\text {th }}$ January and gradually increases from $5^{\text {th }}$ January to $7^{\text {th }}$ January. It maintains almost a steady value from $7^{\text {th }}$ to $10^{\text {th }}$ January, 2015 and slightly increases and decreases on the $11^{\text {th }}$ and $12^{\text {th }}$ January 2015 and then maintains almost a steady value from $12^{\text {th }}-15^{\text {th }}$ January. The SWVD then increases from $15^{\text {th }}-20^{\text {th }}$ January 2015 which suddenly decreases and increases on the $21^{\text {st }}$ and $22^{\text {nd }}$ January with dip downward and upward. The SWVD fluctuating varies until it drops from $29^{\text {th }}$ January to $31^{\text {st }}$ January 2015.

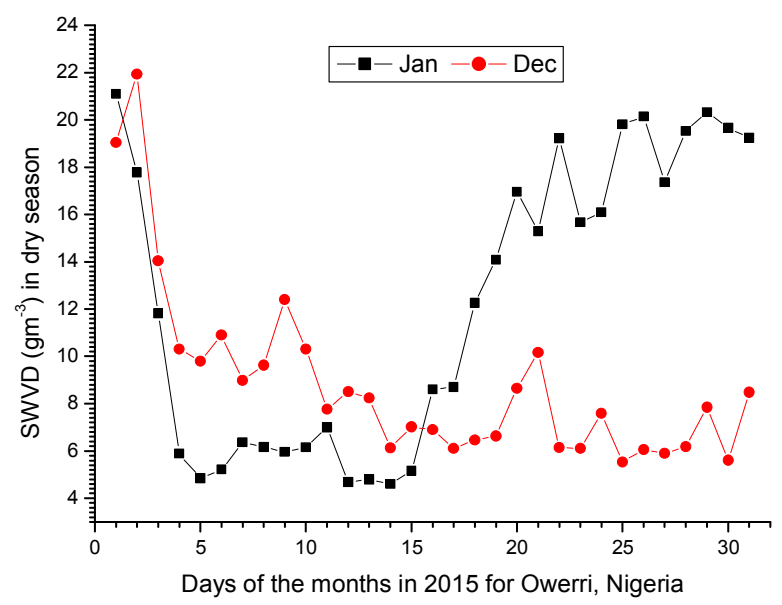

Figure 5. Surface Water Vapour Density during the dry season (January and December) for Owerri, Nigeria.

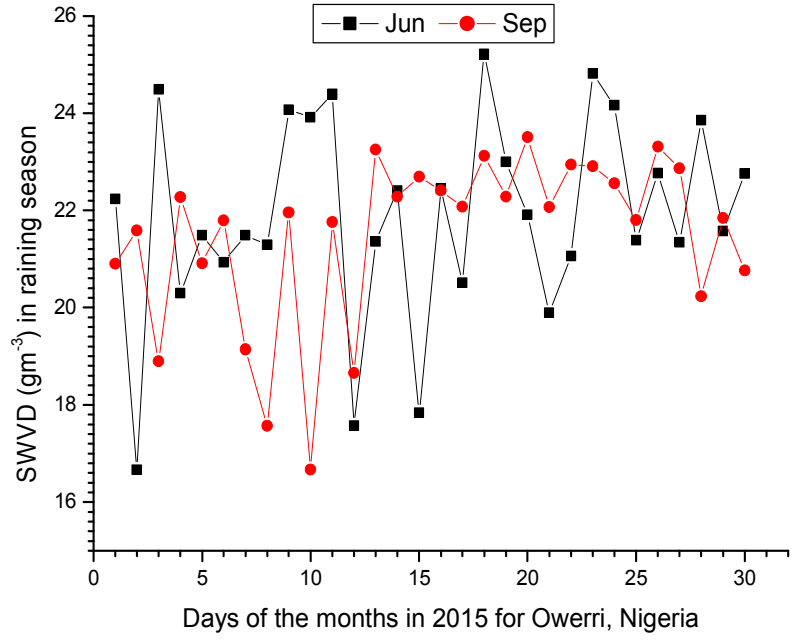

Figure 6. Surface Water Vapour Density during the dry season (June and September) for Owerri, Nigeria.

The maximum and minimum values of SWVD observed in the month of December 2015 are on the $2^{\text {nd }}$ and $30^{\text {th }}$ of December 2015 with SWVD of $21.928 \mathrm{gm}^{-3}$ and $5.602 \mathrm{gm}^{-3}$ respectively. The SWVD gradually increases from $1^{\text {st }}$ to $2^{\text {nd }}$ December and sharply drops from $2^{\text {nd }}$ to $3^{\text {rd }}$ December and consequently to $5^{\text {th }}$ December 2015 . It rise and fall between $5^{\text {th }}$ to $6^{\text {th }}$ December and $6^{\text {th }}$ to $7^{\text {th }}$ December. The SWVD increases from $7^{\text {th }}$ December to $9^{\text {th }}$ December and then drop to $11^{\text {th }}$ December, 2015. The pattern of fluctuation between $11^{\text {th }}$ to $19^{\text {th }}$ December is almost similar. The SWVD rises and fall between $19^{\text {th }}-22^{\text {nd }}$ December 2015 with a dip upward on $21^{\text {st }}$ December 2015. The SWVD then fluctuates changing inconsistently until it gets to $31^{\text {st }}$ December 2015 .

Figure 6 is an extraction of figure 3. The maximum and minimum values of SWVD obtained in the month of June 2015 for the location under study are on the $18^{\text {th }}$ and $2^{\text {nd }}$ of June 2015 with SWVD of $25.215 \mathrm{gm}^{-3}$ and $16.668 \mathrm{gm}^{-3}$ respectively. The SWVD decreases from $22.237 \mathrm{gm}^{-3}$ on the $1^{\text {st }}$ June to its minimum value of $16.668 \mathrm{gm}^{-3}$ on the $2^{\text {nd }}$ June, 2015 and sharply increases from $2^{\text {nd }}$ June to $3^{\text {rd }}$ June and drop on the $4^{\text {th }}$ June with fluctuations of almost an equal amount from $4^{\text {th }}-8^{\text {th }}$ June, 2015 which suddenly increases from $8^{\text {th }}$ June to $9^{\text {th }}$ June with similar fluctuations from $9^{\text {th }}-11^{\text {th }}$ June; there is a sharp fall in the SWVD from $11^{\text {th }}$ to $12^{\text {th }}$ June, 2015 which increases with almost similar pattern of fluctuation from $12^{\text {th }}$ June $-18^{\text {th }}$ June, 2015. The SWVD drops with almost an equal range in values from $18^{\text {th }}-21^{\text {st }}$ June, 2015 and then rise and fall from $21^{\text {st }}-23^{\text {rd }}$ June, 2015 and from $23^{\text {rd }}-25^{\text {th }}$ June, 2015 and fluctuates with almost similar pattern of variation until it gets to $30^{\text {th }}$ June, 2015 .

The maximum and minimum values of SWVD observed in the month of September 2015 for the location under investigation are on the $20^{\text {th }}$ and $10^{\text {th }}$ September, 2015 with SWVD of $23.507 \mathrm{gm}^{-3}$ and $16.671 \mathrm{gm}^{-3}$ respectively. The SWVD slightly increases from $1^{\text {st }}$ to $2^{\text {nd }}$ September, 2015 and suddenly fall and rise on $3^{\text {rd }}$ and $4^{\text {th }}$ September, 2015 with a dip upward; similar observation was noticed between $4^{\text {th }}-6^{\text {th }}$ September, 2015; the SWVD drops from $6^{\text {th }}-8^{\text {th }}$ September, 
2015 at almost equal rate and fluctuates with similar pattern of variation from $8^{\text {th }}-13^{\text {th }}$ September, 2015 ; the pattern of variation are almost similar from $13^{\text {th }}-27^{\text {th }}$ September, 2015 with minor peak values on the $18^{\text {th }}$ and $20^{\text {th }}$ September, 2015. The SWVD drops from $27^{\text {th }}$ September to $28^{\text {th }}$ September, 2015 and suddenly rise and drop on the $29^{\text {th }}$ and $30^{\text {th }}$ September, 2015 respectively.

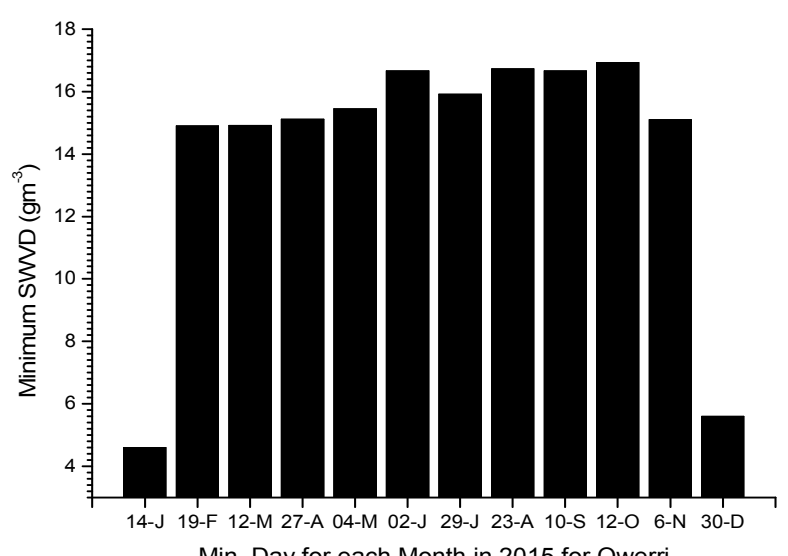

Figure 7. Minimum values of SWVD for each month in 2015 for Owerri, Nigeria.

Figure 7 shows the plot of the minimum values in each month for the location under investigation. The result indicated that the minimum value of SWVD was found to be $4.610 \mathrm{gm}^{-3}$ on the $14^{\text {th }}$ of January in 2015 .

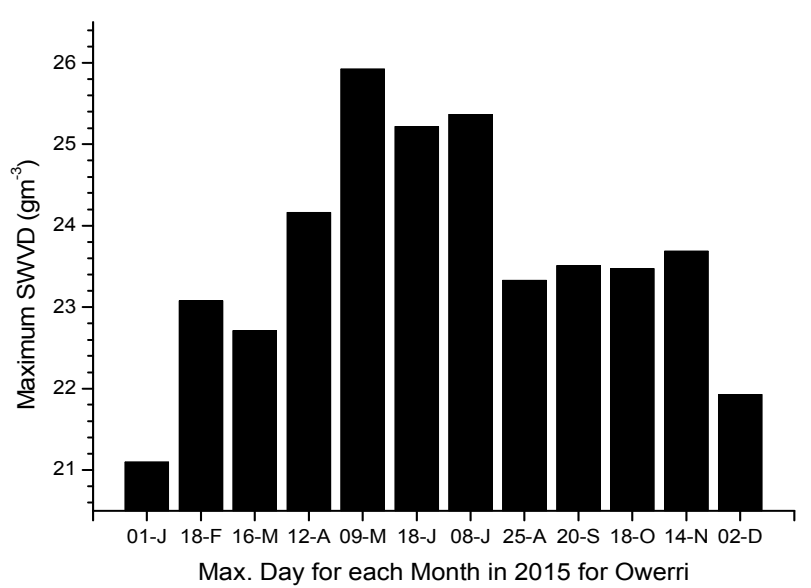

Figure 8. Maximum values of SWVD for each month in 2015 for Owerri, Nigeria.

Figure 8 shows the plot of the maximum values in each month for the location under investigation. The result indicated that the maximum value of SWVD was found to be $25.923 \mathrm{gm}^{-3}$ on the $9^{\text {th }}$ of May in 2015.

Figure 9 shows the monthly variation of SWVD with mean temperature for the location under study. The SWVD at Owerri increases gradually from a minimum value of $14.653 \mathrm{gm}^{-3}$ in the month of January until it gets to its peak value of $21.002 \mathrm{gm}^{-3}$ in the month of June and decreases to August with a dip downward which suddenly increases to September and then drop to December. The mean temperature increases with the SWVD from January and attained its maximum value of $27.813^{\circ} \mathrm{C}$ in the month of March which then decreases continuously to its minimum value in the month of August and increases subsequently to December. The drop in the SWVD as observed in the month of August may be as a result of August break, which is a period of short dryness; it is obvious that it corresponds to the period when the minimum temperature was observed in the study area. The results showed that high and low values of SWVD were observed during the raining and dry seasons respectively; the reverse is the case for the mean temperature.

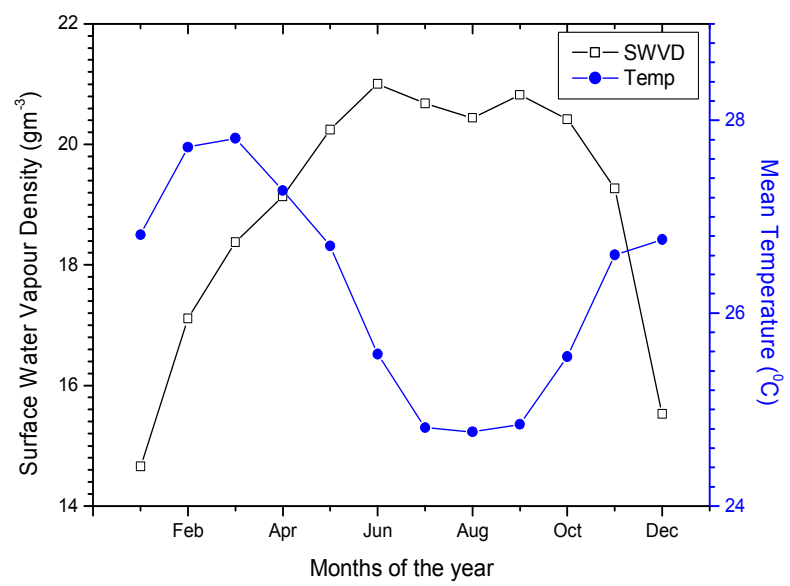

Figure 9. Monthly variation of SWVD with mean temperature at Owerri, Nigeria.

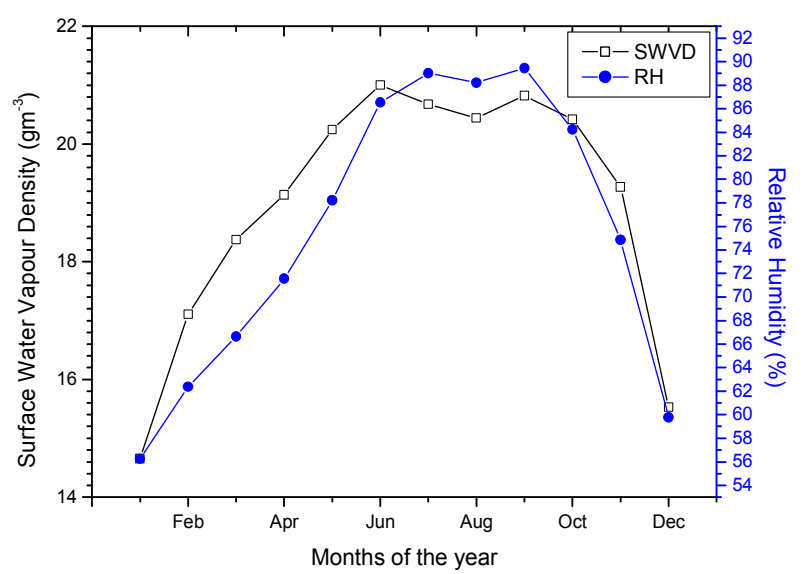

Figure 10. Monthly variation of SWVD with relative humidity at Owerri, Nigeria.

Figure 10 shows the monthly variation of SWVD with relative humidity for the location under study. The relative humidity increases with SWVD from their minimum values in the month of January to June while the relative humidity extends to July. A little dip downward was observed both for the relative humidity and SWVD in the month of August which then increases slightly to September and then drop to December. The observed drop in the values of the relative humidity and SWVD in the month of August may be due to short period of dryness (August break) which is common in the coastal region and most parts of Nigeria. The high values of SWVD observed during the raining season are due to high 
air humidity (close to $90 \%$ ) observed in this part of Nigeria, when the city of Owerri is under the influence of a large quantity of moisture-laden tropical maritime air resulting from continuous migration of inter-tropical discontinuity (ITD) with the sun. Generally, when the dry and dust -laden north-east winds become dominant in December, the dry harmattan season sets in, resulting in lower values of SWVD. The result revealed that high values of SWVD and relative humidity were observed during the raining season and low values during the dry season.

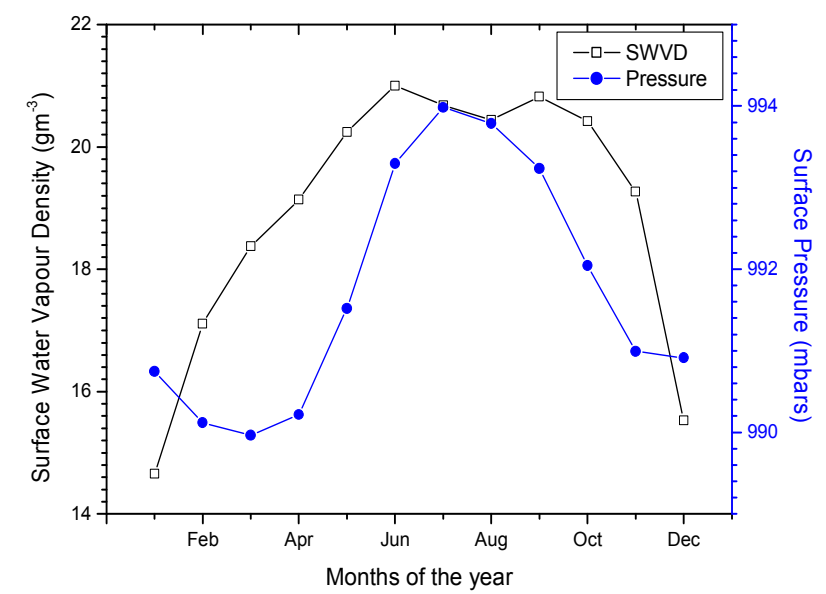

Figure 11. Monthly variation of SWVD with surface pressure at Owerri, Nigeria.

Figure 11 shows the monthly variation of SWVD with surface pressure for the location under study. It was observed that as the SWVD increases from its minimum value in January and attained its maximum value in June; the surface pressure decreases from January and attained its minimum value in March which then increases until it gets to its peak value in the month of July and then decreases to December. The result revealed that high values of SWVD and surface pressure were observed during the raining season and low values during the dry season.

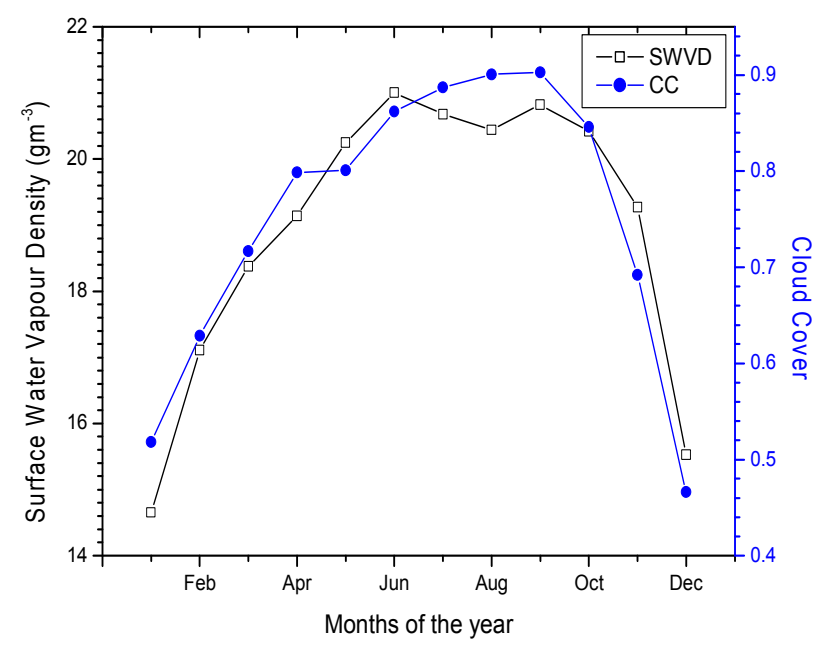

Figure 12. Monthly variation of SWVD with cloud cover at Owerri, Nigeria.

Figure 12 shows the monthly variation of SWVD with cloud cover for the location under study. The cloud cover increases with the SWVD from January to April and maintain almost a constant value from April to May and increases from May and attained its maximum values in the month of September; the cloud cover and SWVD drop from September to December in which the minimum value of cloud cover is in December. The result revealed that high values of SWVD and cloud cover were observed during the raining season and low values during the dry season.

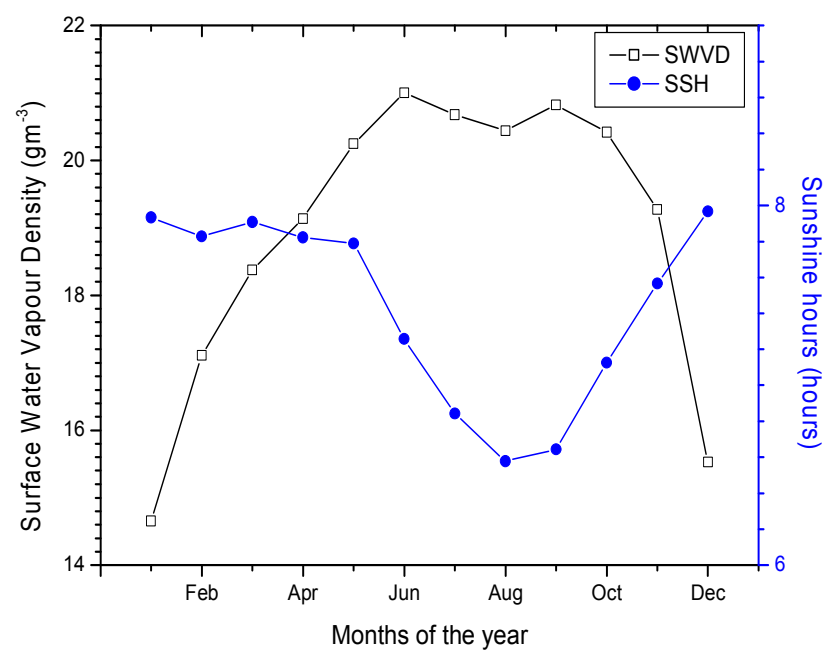

Figure 13. Monthly variation of SWVD with sunshine hours at Owerri, Nigeria.

Figure 13 shows the monthly variation of SWVD with sunshine hours for the location under study. The sunshine hours decreases and increases at almost an equal interval from January to May and then decreases to its minimum value in the month of August which corresponds to the August break observed for the SWVD. The sunshine hours increases from its minimum value in August to its maximum value in December. The result revealed that high values of sunshine hours were observed during the dry season and low values during the raining season which is the reverse case for the SWVD.

The regression equations for the developed models are given by the expressions

$$
\begin{gathered}
S W V D=-30.8+1.16 T_{\text {mean }}+0.257 R H \\
S W V D=24-0.015 S P+13.9 C C \\
S W V D=-94+0.133 S P-2.61 S S H \\
S W V D=5.04+14.9 C C+0.373 S S H
\end{gathered}
$$

Table 1 presents the rundown of the various statistical tests implemented. Based on the $\mathrm{R}^{2}$ the model, equation 14 has the highest value with $99.9 \%$ and is judged the best model. Based on the MBE, the model, equation 17 has the lowest value with overestimation of $0.0831 \mathrm{MJm}^{-2} \mathrm{day}^{-1}$ in the estimated value and is judged the best model. Based on the RMSE the model, equation 14 has the lowest value with $0.1462 \mathrm{MJm}^{-2} \mathrm{day}^{-1}$ and is judged the best model. Based on the MPE, all the models fall within the acceptable range 
(MPE $\leq \pm 10 \%$ ) with the model, equation 17 having the lowest value with underestimation of $0.5504 \%$ in the estimated value and is judged the best model. Based on the
NSE and IA the model, equation 14 has the highest value with $99.8402 \%$ and $99.9611 \%$ respectively and is judged the best model.

Table 1. Validation of the surface water vapour density for Owerri under different statistical test.

\begin{tabular}{lllllll}
\hline Models & $\mathbf{R}^{\mathbf{2}} \mathbf{( \% )}$ & MBE $\left(\mathbf{g m}^{-\mathbf{3}}\right)$ & RMSE $\left(\mathbf{g m}^{-\mathbf{3}}\right)$ & MPE (\%) & NSE $(\%)$ \\
\hline Eqn 14 & 99.9 & 0.1259 & 0.1462 & -0.6739 & 99.8402 \\
Eqn 15 & 92.0 & 0.5963 & 0.8321 & -3.3033 & 94.8235 \\
Eqn 16 & 52.4 & -0.4875 & 1.5002 & 1.9285 & 93.9611 \\
Eqn 17 & 92.3 & 0.0831 & 0.5750 & -0.5504 & 98.8499 \\
\hline
\end{tabular}

Table 2. Ranking of the evaluated surface water vapour density for Owerri as per Statistical test.

\begin{tabular}{|c|c|c|c|c|c|c|c|}
\hline Models & $\mathbf{R}^{2}$ & MBE & RMSE & MPE & NSE & IA & Total rank \\
\hline Eqn 14 & 1 & 2 & 1 & 2 & 1 & 1 & 8 \\
\hline Eqn 15 & 3 & 4 & 3 & 4 & 3 & 3 & 20 \\
\hline Eqn 16 & 4 & 3 & 4 & 3 & 4 & 4 & 22 \\
\hline
\end{tabular}

The ranking of the models (Table 2) was done based on the validation of the models (Table 1). The total ranks obtained by the different models ranged from 10 to 22 . Based on the overall results the model, equation 14 was found the best and most suitable for estimating Surface water vapour density for the study area.

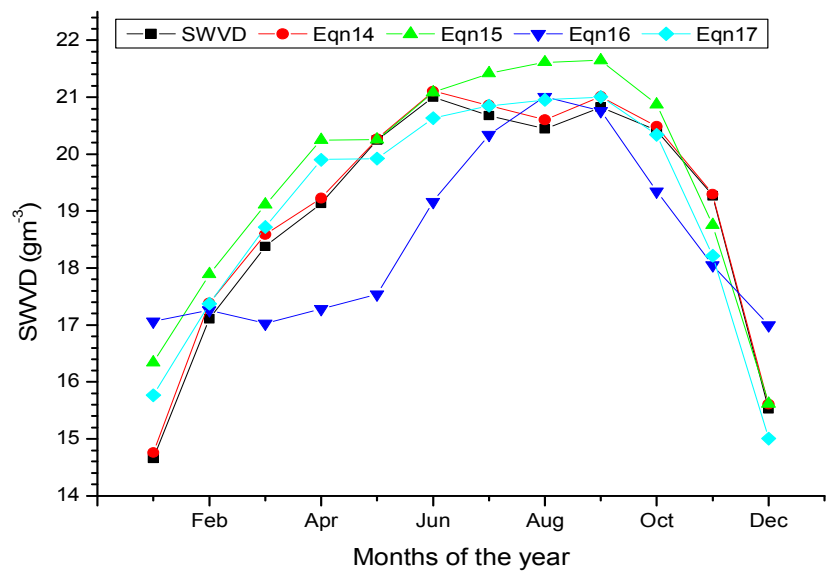

Figure 14. Comparison between the SWVD and estimated SWVD models for Owerri, Nigeria.

Figure 14 shows the comparison between the SWVD and estimated SWVD models for the location under investigation. The SWVD underestimated the calculated models in the months of January, February and August. The model (Eqn
16) underestimated the SWVD and other calculated SWVD in the months from March to July and from September to November; the model (Eqn 16) also overestimated the SWVD and other calculated SWVD in the months of January and December. The model (Eqn 15) overestimated the SWVD and other calculated models in the months from February to April and from July to October.

Figure 15 shows that the model (Eqn 14) gives the best fitting with the SWVD as compared to other calculated models and therefore was recommended for estimating SWVD for Owerri, Nigeria.

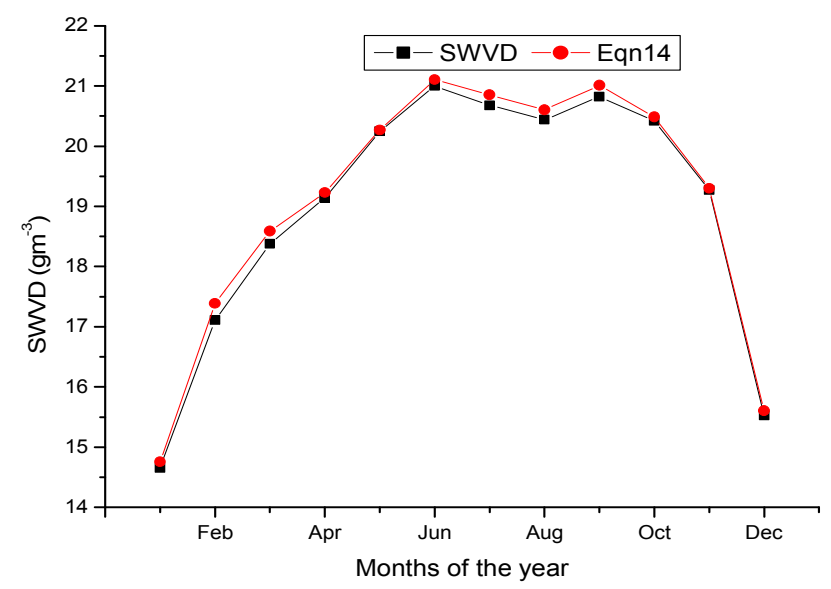

Figure 15. Comparison between the SWVD and recommended estimated SWVD model for Owerri, Nigeria.

Table 3. Descriptive statistical analysis for the SWVD and other parameters for Owerri, Nigeria.

\begin{tabular}{lllllll}
\hline & Range & Minimum & Maximum & Sum & Kurtosis \\
\cline { 2 - 6 } & Statistic & Statistic & Statistic & Statistic & Statistic \\
\hline SWVD & 6.3487 & 14.6535 & 21.0022 & 227.6859 & -1.1040 \\
T $_{\text {mean }}$ & 3.0438 & 24.7688 & 27.8125 & 315.2344 & -0.1500 \\
RH & 33.2100 & 56.2431 & 89.4531 & 907.0988 & -0.3170 & -0370 \\
SP & 4.0187 & 989.9650 & 993.9838 & 11900.8300 & 0.3980 \\
CC & 0.4364 & 0.4662 & 0.9025 & 9.0183 & -1.4530 & -1.4850 \\
SSH & 1.3891 & 6.5781 & 7.9672 & 89.2624 & -1.5250 & -0.6410 \\
\hline
\end{tabular}

The results shown in Table 3 showed that the surface water vapour density, mean temperature, relative humidity, cloud cover and sunshine hours data spread out more to the left of their mean value (negatively skewed), while the surface pressure data spread out more to the right of their mean value (positively skewed). The mean temperature, relative humidity 
and surface pressure data seem to have a quassi-Gaussian distribution. Skewness of exactly zero is quite not likely for real world data [16]. The surface water vapour density, cloud cover and sunshine hours data are more divergent away from the normal distribution. It can be seen from Table 3 that the surface water vapour density data have positive kurtosis which indicates a relatively peaked distribution and possibility of a leptokurtic distribution while the other terms (mean temperature, relative humidity, surface pressure, cloud cover and sunshine hours) data have negative kurtosis which indicates a relatively flat distribution and possibility of platykurtic distribution.

\section{Conclusion}

In this present study, the issue of estimating SWVD and its variation with other meteorological parameters during the period of sixteen years $(2000-2015)$ and daily variation of SWVD in each month for the year 2015 has been addressed using monthly average and daily average meteorological data obtained from the European Centre for Medium-Range Weather Forecasts (ECMWF) at $2 \mathrm{~m}$ height for Owerri (Latitude $5.48^{\circ} \mathrm{N}$, Longitude $7.00^{\circ} \mathrm{E}$, and $91 \mathrm{~m}$ above sea level) Imo state located in the South Eastern, Nigeria. The results of this study revealed that high values of SWVD are recorded during the raining season and low values during the dry season. It was observed that the maximum and minimum average values of SWVD of $21.002 \mathrm{gm}^{-3}$ and $14.653 \mathrm{gm}^{-3}$ were found in the months of June and January during the raining and dry seasons respectively. The highest value of surface water vapour density was observed on $9^{\text {th }}$ May, 2015 and the lowest on $14^{\text {th }}$ January, 2015 during the period under investigation. Four simple two variable correlation models were developed and was statistically tested using statistical indices of coefficient of correlation, mean bias error (MBE), root mean square error (RMSE), mean percentage error (MPE), Nash - Sutcliffe Equation (NSE) and index of agreement (IA) from which the model that relates temperature and relative humidity was found more suitable for estimating surface water vapour density (SWVD) for the location under investigation. The results of the descriptive statistical analysis revealed that the surface water vapour density, mean temperature, relative humidity, cloud cover and sunshine hours data spread out more to the left of their mean value (negatively skewed), while the surface pressure data spread out more to the right of their mean value (positively skewed). The surface water vapour density data have positive kurtosis which designated a relatively peaked distribution and likelihood of a leptokurtic distribution while the mean temperature, relative humidity, surface pressure, cloud cover and sunshine hours data have negative kurtosis which designated a relatively flat distribution and likelihood of platykurtic distribution. This study is vital to hydro meteorologists and other relevant stakeholders and investors that need to know quantitatively the amount of SWVD and other pertinent information regarding SWVD for the location.

\section{Acknowledgements}

The authors wish to thank the European Centre for Medium-Range Weather Forecasts (ECMWF) for providing all the necessary meteorological data used in this study. The contributions and suggestions of the anonymous reviewers are well appreciated.

\section{References}

[1] AGU (1995). American Geophysical Union's Special Report on Water Vapour in the Climate System. Washington, DC 20009.

[2] Adeyemi, B and Ogolo, E. O (2014). Diurnal and seasonal variations of surface water vapour density over some meteorological stations in Nigeria. Ife Journal of Science vol. 16: no. 2.

[3] Gerding, M., Christopher, R and Neuber, R (2002). Tropospheric water vapour observations by ground based Lidar. Sixth Ny-Alesund International scientific seminar, NPI report series, NorskPolarinstituH.

[4] Ajayi, G. O (1989). Physics of the tropospheric radio propagation. Proceedings of the ICTP College on Theoretical and Experimental Radio Propagation Physics, 6-24 February 1989, Trieste, Italy.

[5] Harries, J. E (1997). Atmospheric radiation and atmospheric humidity. Quarterly Journal of Meteorol. Society.123: 21732186.

[6] Schulz, J., Albert, P., Behr, H. D et al (2009). Operational climate monitoring from space: the EUMETSAT satellite application facility on climate monitoring (CM-SAF). Atmos. Chem. Phys. Discussion. net/8/8517/2008/.

[7] Wentz, F. J and Schabel, M (2000). Precise Climate Monitoring Using Complementary Satellite Data Sets. Nature.403: 414-416.

[8] Hegg, D. A., Hobbs, P. V., Gasso, S et al (1996). Aerosol measurements in the Arctic relative to direct and indirect radiative forcing J. Geophy. Res. 101: 23349-23363.

[9] Ramanathan, V., Crutzen, P. J., Kiehl, J. T et al (2001). Aerosols, climate and the hydrological cycle. Sci., 294: 2119-2124.

[10] IPCC (2001). Inter governmental Panel on Climate change. Third Assessment Report: Climate change 2001. WGI: The scientific basis, summary for policy makers, Geneva, Switzerland.

[11] Okorie, F. C., Okeke, I., Nnaji, A et al (2012). Evidence of Climate Variability in Imo State of Southeastern Nigeria. Journal of Earth Science and Engineering. 2 (2012): 544-553.

[12] Okorie, F. C (2010). Great Ogberuru in Its Contemporary Geography, Cape Publishers, Owerri, Nigeria.

[13] El-Sebaii, A and Trabea, A (2005). Estimation of Global Solar Radiation on Horizontal Surfaces Over Egypt, Egypt. J. Solids. 28(1): 163-175.

[14] Chen, R., Ersi, K., Yang, J et al (2004). Validation of five global radiation Models with measured daily data in China. Energy Conversion and Management.45, 1759-1769. 
[15] Merges, H. O., Ertekin, C and Sonmete, M. H (2006). Evaluation of global solar radiation Models for Konya, Turkey. Energy Conversion and Management. 47: 3149-3173.

[16] Akpootu, D. O., Iliyasu, M. I., Mustapha, W et al (2017). The Influence of Meteorological Parameters on Atmospheric Visibility over Ikeja, Nigeria. Archives of Current Research International. 9(3): 1-12. doi: 10.9734/ACRI/2017/36010.
[17] Hejase, H. A. N and Assi, A. H (2011). Time-Series Regression Model for Prediction of Monthly and Daily Average Global Solar Radiation in Al Ain City-UAE. Proceedings of the Global Conference on Global Warming held on 11 - 14 July, 2011, Lisbon, Portugal. Pp 1-11. 